\title{
Relationships between Social Support and Social Image Concerns in Turkish Women with Breast Cancer
}

\author{
Ayse Ozkaraman ${ }^{1 *}$, Ilkay Culha ${ }^{1}$, Zehra Cicek Fadıloglu ${ }^{2}$, Nedime Kosgeroglu ${ }^{3}$, \\ Serap Gokce ${ }^{4}$, Guler Balcı Alparslan ${ }^{1}$
}

\begin{abstract}
Background: Breast cancer is one of the most common cancer types in women and is amongst the most devastating and stressful events in the life of women. The external appearance of breast cancer patients usually changes due to the surgical and/or medical therapies used. An association may be found between social support perception and social appearance anxiety in patients with breast cancer in the period after mastectomy. Therefore, this study investigated the social appearance anxiety and social support status in women with breast cancer in our country. Materials and Methods: A descriptive cross-sectional study was conducted in breast cancer patients undergoing treatment or follow-up in Medical Oncology and General Surgery departments. Results: The mean age of the participants was $\mathbf{5 1 . 1 3} \pm 8.48$ years (range, 24-74 years) with nearly half of the patients $(\mathbf{4 0 . 6 \% )}$ aged 40-50 years. Of the patients, $39.1 \%$ had stage 3 breast cancer. The mean score on Cancer Patient's Social Support Scale (CPSSS) was $134.85 \pm 9.35$, and there was a significant difference in CPSSS total scores between the age groups, educational levels, self-reported income levels and stage of disease $(p<0.05)$. The mean Social Image Anxiety Scale (SIAS) score was found to be $34.30 \pm 9.35$ (min:16, max:66) in women participating in this study. The CPSSS and SIAS scores of the participants were inversely correlated, and the SIAS score was found to decrease with the increasing CPSSS score but with no statistically significant difference $(r=-0.110, p=0.217)$. Conclusions: Social appearance anxiety is higher in the patients with poor social support
\end{abstract}

Keywords: Breast cancer - social support - social image anxiety

Asian Pac J Cancer Prev, 16 (5), 1795-1802

\section{Introduction}

The prognosis of breast cancer-one of the most common cancers in women increasingly improves due to the advances in early diagnosis and effective treatment of the disease (Dincer et al., 2007). The incidence of breast cancer has increased gradually with 45.1 per hundred thousand people in Turkey and was estimated to be 235 030 cases in the United States in 2014 (Republic of Turkey Ministry of Health Statistics, 2012; American Cancer Society, 2014).

Breast cancer is a devastating and stressful event in a woman's life and leads to deterioration in physical, social and role functions (Michael et al., 2000; Bilge and Cam, 2008). Particularly during the chemotherapy treatment in the first postoperative year, women usually report decreased attractiveness and loss of sexual function due to the changes in body image (Fobair et al., 2006; National Mastectomy and Breast Cancer Reconstriction Audit, 2011; Winters et al., 2011). Dogan (2010) has suggested that many people prefer to communicate mostly with attractive individuals. Therefore, people usually spend effort to make an effective impression on others and to appear more attractive with feeling anxious if they are concerned about not having an effective impression (Dogan, 2010). Ucar and Uzun (2008) have found that women have less bodily perception, self-esteem and spouse-compliance after the mastectomy compared to healthy women and that self-esteem and spousecompliance increase with increased bodily perception.

As in many countries, the female breast represents sexuality, aesthetic appearance, baby food, love and motherhood in Turkey. Therefore, the thought of losing the breast causes severe psychological problems in women (Okanlı, 2004; Cavdar, 2006; Abu-Helalah et al., 2014; Manandar et al., 2014; ). The social support from the husband and close environment is important in overcoming all these problems (Kinsinger et al., 2011; Akdeniz, 2012). Social support has a key role in adapting to crises that emerge in life, such as breast cancer (Tan and Karabulut, 2005; Shelby et al., 2008; Rizalar et al., 2014). Several studies have suggested that regular psychosocial support provided to the cancer patient has positive effects on the prognosis of disease and quality of life and decreases the problems experienced by the patient (Aslan et al., 2007; Bahar, 2006; Babaoglu and Oz, 2003).

${ }^{1}$ Eskisehir Health High School, Eskisehir Osmangazi University, Eskisehir, ${ }^{2}$ Ege University, Faculty of Nursing, Izmir, ${ }^{3}$ Adnan Menderes University, Aydin Health High Schhol, Aydın, Turkey*For correspondence: aozaydin26@hotmail.com 
Based on all this information, an association may be found between social support perception and social appearance anxiety in patients with breast cancer during the period after mastectomy. Therefore, this study investigated social appearance anxiety and social support status in women with breast cancer in our country.

\section{Materials and Methods}

Study design

Descriptive cross-sectional study

\section{Study population and sample}

The study population included breast cancer patients who were followed and treated in a hospital in the province of Eskisehir and fulfilled the inclusion criteria.

Breast cancer patients aged 18-74 years agreed to participate in the study, were literate, had no communication problems, had no psychiatric disease and were undergoing follow-up and treatment after mastectomy.

\section{Data collection tools}

Data were collected by using a patient identification form, Cancer Patient's Social Support Scale (CPSSS) and Social Image Anxiety Scale (SIAS).

The patient identification form consisted of 22 items about sociodemographic characteristics (age, gender, educational level, marital status, social insurance, job, employment status, income level, residence and people living in the house), disease-related characteristics (disease stage, treatment modality, presence of co-morbidities) and presence of social support.

The Cancer Patient's Social Support Scale (CPSSS) was developed by Berrin Eylen to determine the type and level of social support provided to the patients by their family. The reliability and validity of the scale was established in Turkey in 2002 with a Cronbach's alpha value of 0.92 . The scale has three subdimensions: informational support, emotional support and reliance support. Patients are asked to mark the level of support they receive from the family on a 5-point grading scale. The scale consisted of 35 items with 13 negative and 22 positive sentences. The perceived social support score is calculated by adding the sum of the scores of positive sentences with the sum of the inverted scores of negative sentences. Higher total scores on this scale indicate a higher perceived social support from the family (Eylen, 2002).

Social Image Anxiety Scale (SIAS) is a self-report scale developed by Hart et al. (2008) to measure the emotional, cognitive and behavioural concerns of a patient about his/her appearance. The reliability and validity of the scale were established in Turkey in 2010 by Dogan with a Cronbach's alpha value of 0.85 . The scale consists of 16 items graded by a 5 -point Likert scale ( $1=$ definitely not appropriate to $5=$ completely appropriate). The first item on the scale is encoded inversely. Higher scores on this scale indicate higher anxiety about appearance (Dogan, 2010).

\section{Data collection}

Between January 1, 2012 and January 30, 2013, a total of 143 female patients in follow-up or treatment in the outpatient clinics of general surgery and medical oncology and outpatient chemotherapy unit fulfilled the inclusion criteria. Of these patients, 12 and 3 were excluded due to unwillingness to participate in the study and being illiterate, respectively. The remaining 128 patients were included in the study, and data collection forms were completed using face-to-face interviews. All procedures were performed by the researchers throughout the study.

\section{Evaluation of data}

Data were analysed using IBM SPSS Statistics 21.0 Package. Continuous data were expressed as the mean \pm standard deviation, and the categorical data were expressed as percentage (\%).To compare the variables with scale scores, one-way ANOVA was used for normal distributed data, and the Kruskal-Wallis test was used for non-normal distributed data. The association between the scores on SIAS, CPSSS and CPSSS subdimensions was evaluated by Spearman correlation analysis. Statistical significance was set at $\mathrm{p}<0.05$.

\section{Ethical aspects of the study}

Necessary written permissions were granted by an ethical committee, hospital administration and the participants.

Permission was also granted by Berrin Eylen and Tayfun Dogan to use the Cancer Patient's Social Support Scale and Social Image Anxiety Scale in the study.

\section{Results}

The mean age of the participants was $51.13 \pm 8.48$ years (range, 24-74 years) with nearly half of the patients (40.6\%) aged $40-50$ years. Of the patients, $89.8 \%$ were married, $46 \%$ were primary school graduates, $74.2 \%$ were housewives in which most were unemployed (91.4\%), $71.9 \%$ were living at the city centre and $62.5 \%$ were living with their spouse. In regard to income level, $51.6 \%$ of the female patients expressed that their income met their expenses. Of the patients, $39.1 \%$ had stage III breast cancer, and $90.6 \%$ were informed about breast cancer surgery.

In regard to the social support status of the patients, $28.1 \%$ of the female patients received social support from all their children, parents, siblings and friends; $82.8 \%$ received support from the hospital; $38.3 \%$ received support from the doctors and $35.2 \%$ received support from nurses. However, $14.1 \%$ and $11.7 \%$ of the patients reported no social support from a health care provider and an institution, respectively.

The mean score on CPSSS was $134.85 \pm 9.35$ (min:105, max:159), and the subscores for reliance support and emotional support were higher than that for informational support. There was a significant positive relationship between CPSSS total score and CPSSS subscores (ISS: $\mathrm{r}=0.569, \mathrm{p}<0.001),($ ESS: $\mathrm{r}=0.807, \mathrm{p}<0.001)$, (RSS: $\mathrm{r}=0.228, \mathrm{p}=0.009$ ) (Table 3 ).

There was a significant difference in CPSSS total scores between the age groups $(\mathrm{KW}=11.200, \mathrm{p}=0.011)$ (Table 1) with a higher mean CPSSS score in women younger than 


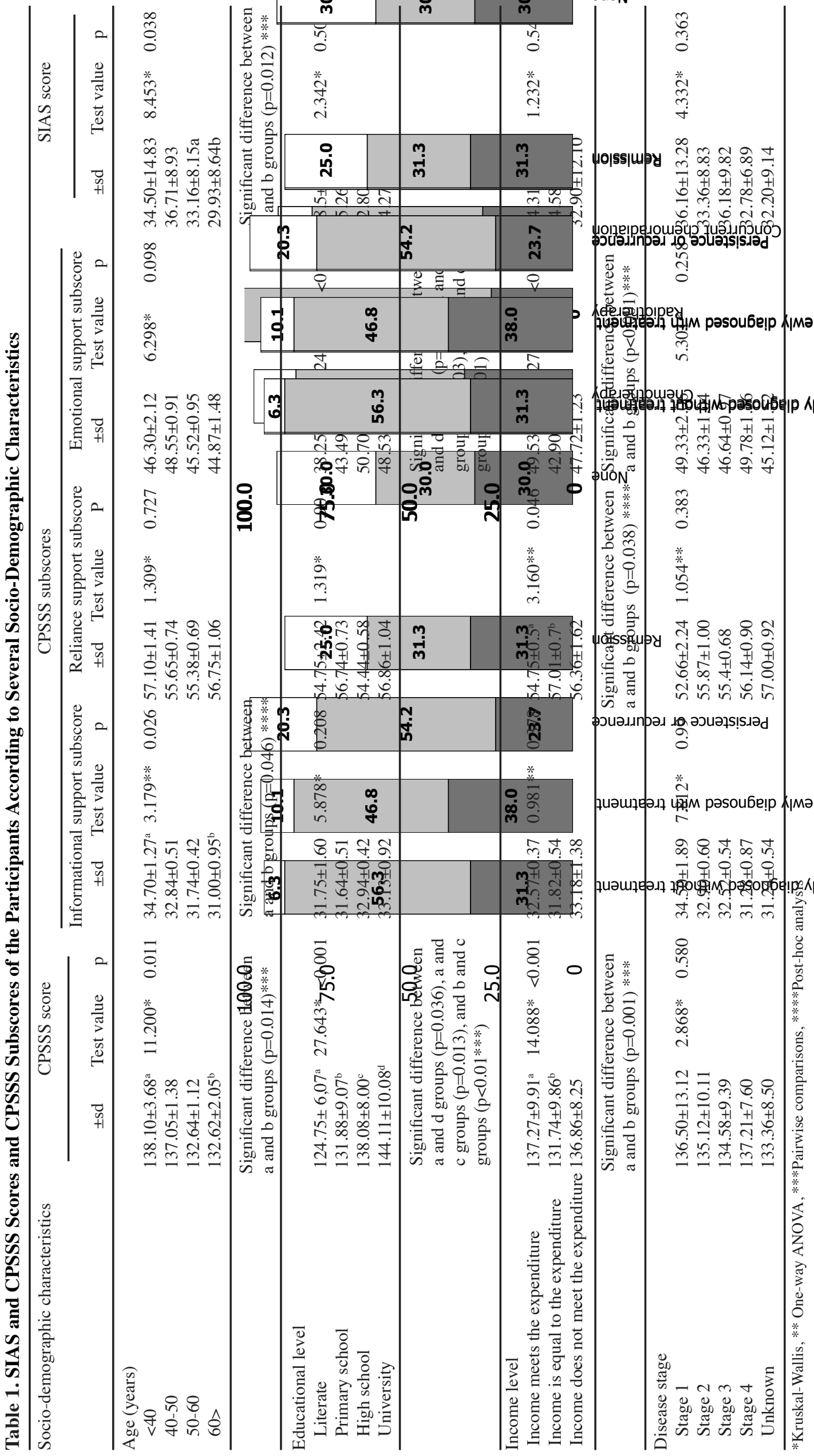


Ayse Ozkaraman et al

40 years compared to those older than 60 years $(p=0.014)$ (Table $1)$. There was also a significant difference in informational support scores (ISS) between the age groups $(\mathrm{t}=3.179, \mathrm{p}=0.026)$ with women aged $>60$ years having a lower ISS compared to the women aged $<40$ years $(\mathrm{p}=0.046)$ (Table 1). No significant difference was found between the age groups in terms of emotional and reliance support scores (ESS and RSS) (ESS: KW=6.298, p=0.098; RSS: $\mathrm{KW}=1.309, \mathrm{p}=0.727$ ) (Table 1).

There was a significant difference between CPSSS scores and educational level of the women, and CPSSS scores increased with increasing educational level (KW=27.643, p<0.001) (Table 1). Pairwise comparison revealed differences between literate women and university graduates $(\mathrm{p}=0.036)$, literate women and high school graduates $(\mathrm{p}=0.013)$, and primary school graduates and high school graduates $(\mathrm{p}<0.001)$. Educational level was significantly associated with the ESS score ( $\mathrm{KW}=24.481, \mathrm{p}<0.01)$ but not with ISS $(\mathrm{KW}=5.878, \mathrm{p}=0.208)$ and RSS (KW=1.319, $\mathrm{p}=0.90)$. Differences existed between literate women and university graduates $(\mathrm{p}=0.04)$, literate women and high school graduates $(\mathrm{p}=0.03)$, and primary school graduates and high school graduates $(\mathrm{p}<0.01)$ (literate women: $38.25 \pm 11.32 /$ primary school graduates: $43.49 \pm 0.70$ / high school graduates: $50.70 \pm 0.71 /$ university graduates: $48.53 \pm 2.14$ ) (Table 1).

The CPSSS scores were found to differ significantly between selfreported income levels. Women reporting their income level as "income meets the expenditure" had higher CPSSS scores compared to other women $(\mathrm{KW}=14.088$, $\mathrm{p}<0.001$ ) (Table 1). Self-reported income level was significantly associated with RSS ( $\mathrm{t}=3.160$, $\mathrm{p}=0.046)$ and ESS $(\mathrm{KW}=27.351$, $\mathrm{p}<0.001)$ but not with ISS $(\mathrm{t}=3.160$, $\mathrm{p}=0.046)$ (Table 1). In the post hoc analysis, RSS was higher in women reporting their income level as "income is equal to the expenditure" compared to those

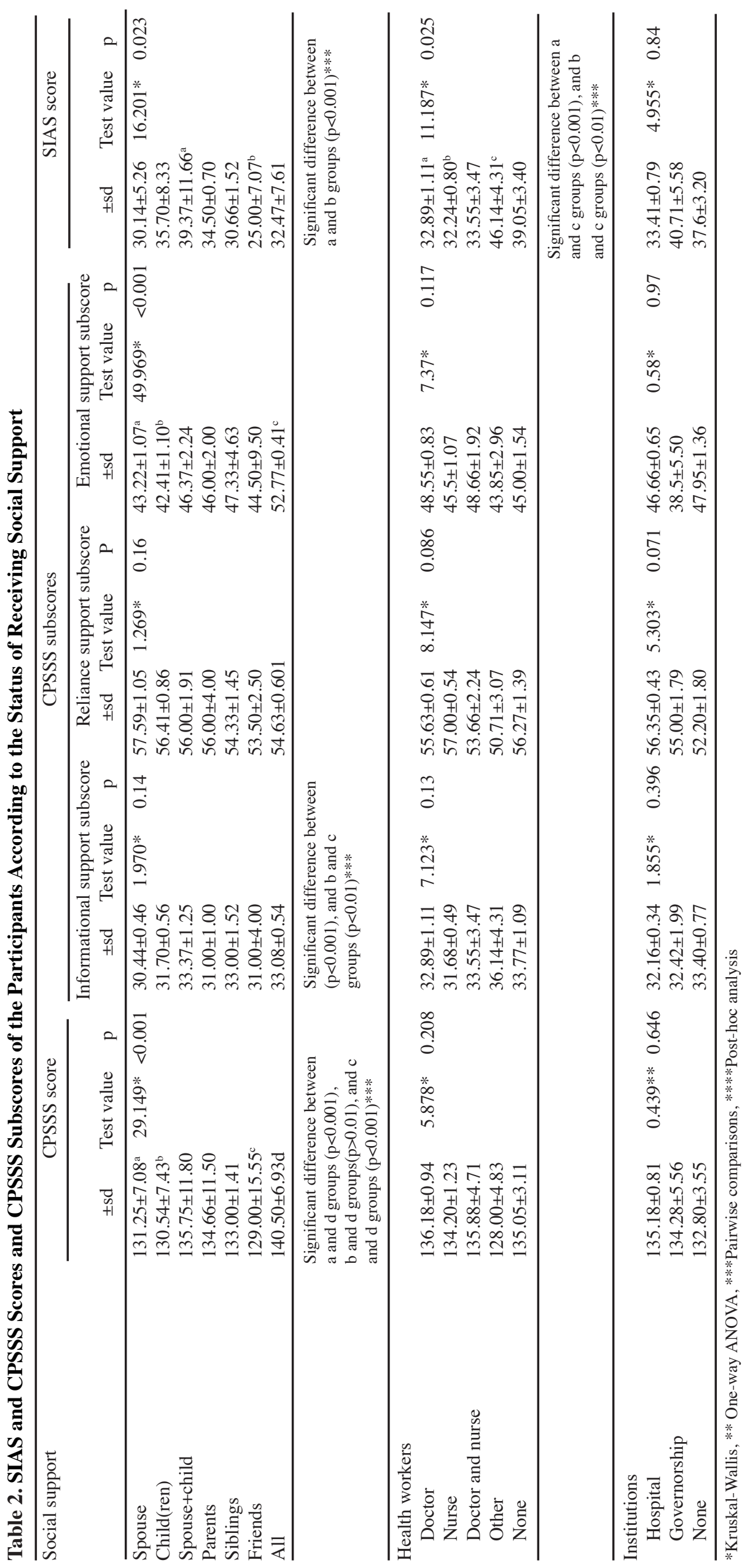


reporting "income meets the expenditure" $(\mathrm{p}=0.038)$. ESS was higher in women reporting their income level as "income meets the expenditure" compared to those reporting "income is equal to the expenditure" or "income does not meet the expenditure" $(49.53 \pm 0.73,42.90 \pm 0.87$ and $47.72 \pm .23$, respectively) (Table 1 ).

In terms of the stage of the disease, the CPSSS scores were higher in women with stage 4 disease with no significant difference between the disease stages in CPSSS score $(\mathrm{KW}=2.868, \mathrm{p}=0.580)$, ISS $(\mathrm{KW}=7.812$, $\mathrm{p}=0.99), \operatorname{RSS}(\mathrm{t}=1.054, \mathrm{p}=0.383)$ and $\mathrm{ESS}(\mathrm{KW}=5.301$, $\mathrm{p}=0.258)$ (Table 1).

All participants received a form of support from their family members or friends. The CPSSS score was higher in women receiving social support from all individuals compared to those receiving social support from any individual (KW=29.149, $\mathrm{p}<0.001$ ) (Table 2). Although ISS and RSS did not differ between the groups according to the individual providing social support, ESS was significantly higher in women receiving social support from all individuals compared to those receiving only from a spouse or children $(\mathrm{KW}=49.969, \mathrm{p}<0.001)$ (Table 2).

If the CPSSS scores were analysed according to the social support from health professionals or institutions, no significant difference was found in the CPSSS scores between women having social support and no support $(\mathrm{KW}=5.878, \mathrm{p}=0.208),(\mathrm{F}=0.959, \mathrm{p}=0.386)$ (Table 2).

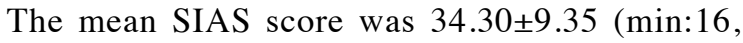
max:66) in the women in this study. The mean SIAS score was significantly different between the age groups with a higher SIAS score in women aged 40-50 years compared to those aged $>60$ years $(\mathrm{KW}=8.453, \mathrm{p}=0.038)$ (Table 1$)$.

In terms of educational level, the SIAS score was slightly higher amongst women who graduated from primary school, but the difference was not significant (KW=6.155, p=0.188) (Table 1).

Women reporting their income level as "income meets the expenditure" and "income is equal to the expenditure" had similar SIAS scores, and the scores were higher than that of women reporting "income does not meet the expenditure". However, this difference did not reach statistical significance $(\mathrm{KW}=1.232, \mathrm{p}=0.540)$ (Table 1).

Higher SIAS scores were found amongst women with stage 3 disease; however, the score was lower amongst those who had no information about the stage of their disease, and there was no significant difference between the disease stages in terms of the mean SIAS scores $(\mathrm{KW}=4.332$, $\mathrm{p}=0.363$ ) (Table 1).

All participants received some form of support from family members and/or friends. The SIAS score was higher amongst women receiving support from the spouse and/ or children, and it was lower amongst women receiving support only from friends with a significant difference between the groups $(\mathrm{KW}=16.201, \mathrm{p}=0.023$ ) (Table 2).

In terms of receiving social support from healthcare workers or any institution, the SIAS score was higher in women receiving social support from the healthcare workers other than healthcare professionals (caregiver, advisory officer) and in women receiving no social support. However, the score was lower in women receiving social support only from healthcare professionals
Table 3. Correlation between CPSSS score and SIAS Score and CPSSS Subscores

\begin{tabular}{|c|c|c|c|c|c|}
\hline & 1 & 2 & 3 & 4 & 5 \\
\hline \multicolumn{6}{|c|}{ CPSSS score } \\
\hline \multicolumn{6}{|c|}{$\mathrm{r}$} \\
\hline \multicolumn{6}{|l|}{$\mathrm{p}$} \\
\hline \multicolumn{6}{|c|}{ Informational Support subscore } \\
\hline $\mathrm{r}$ & \multicolumn{5}{|c|}{0.569} \\
\hline $\mathrm{p}$ & \multicolumn{5}{|c|}{0.000} \\
\hline \multicolumn{6}{|c|}{ Emotional Support subscore } \\
\hline $\mathrm{r}$ & 0.807 & 0.318 & & & \\
\hline $\mathrm{p}$ & 0.000 & 0.000 & & & \\
\hline \multicolumn{6}{|c|}{ Reliance Support subscore } \\
\hline $\mathrm{r}$ & 0.228 & -0.114 & -0.216 & & \\
\hline $\mathrm{p}$ & 0.009 & 0.200 & 0.014 & & \\
\hline \multicolumn{6}{|c|}{ SIAS score } \\
\hline $\mathrm{r}$ & -0.110 & 0.068 & -0.001 & -0.352 & \\
\hline $\mathrm{p}$ & 0.217 & 0.445 & 0.994 & 0.000 & \\
\hline
\end{tabular}

$(\mathrm{KW}=11.187, \mathrm{p}=0.025)$. The SIAS scores did not differ significantly between women receiving and not receiving social support from the office of the governor or from a healthcare institution (KW=5.474, $\mathrm{p}=0.065$ ) (Table 2).

The CPSSS and SIAS scores of the participants were inversely correlated, and the SIAS score was found to decrease with an increasing CPSSS score but was not statistically significant $(\mathrm{r}=-0.110, \mathrm{p}=0.217)$ (Table 3$)$. The SIAS score increased with the decreasing emotional and reliance support subscores [ $(\mathrm{r}=-0.001, \mathrm{p}=0.994)$ and $(\mathrm{r}=-0.352, \mathrm{p}<0.001)$, respectively] and with the increasing informational support subscore $(r=0.068, p=0.445)$ (Table $3)$.

\section{Discussion}

Social support has an important role in improving the quality of life in cancer patients and is an effective strategy for fighting the disease (Usta, 2012). Patients receiving adequate social support consider that they are loved and respected, they will get help if they need and they are satisfied with their relationships; therefore, social support represents a key factor in maintaining health (Ardahan, 2006; World Health Organization, 2004).

In the patients participating in this study, the mean age was $51.13 \pm 8.48$ years, and most were married and primary school graduates. Of the patients, $39.1 \%$ had stage III breast cancer and $90.6 \%$ were informed about breast cancer surgery. In the study of Ogce et al (2007) it was found that mean age of women was 49.8 years and women had primary education levels (Ogce et al 2007). Alacacioglu et al (2014) found that mean age of women with breast cancer was 44.7 years (range, 30-60 years), of the women, $40 \%$ had local diseases, $48 \%$ had advanced local diseases, $12 \%$ advanced level diseases (Alacacioglu et al 2014). Most patients were older than 40 years, which supports previous data about increased breast cancer incidence with age (Abeloff et al., 2008). Moreover, this finding is very important for Turkey because women constitute $20 \%$ of the individuals aged 45-64 years and 7.9\% of the individuals aged 65-84 years (Turkish Statistical Institute, 2013).

Of the participants, $9.4 \%$ received social support only 
from friends, and the remaining participants $(90.6 \%)$ received social support from one of and/or all family members. Kinsinger et al. (2011) and Ozyurt (2007) found that most patients receive social support from their spouses compared to child(ren) and sibling(s). However, Sahin et al. (2009) reported that cancer patients mostly receive care from children followed by the spouses, and $27.9 \%$ of the caregivers meet all needs of the patients whereas $39.3 \%$ and $32.8 \%$ of the caregivers provide financial and psychological support, respectively. In study of Ogce et al (2007), perception of social support of patients who experience stress in family has been determined lower than those who don't experience stress in family (Ogce et al, 2007). During the cancer process, family relationships improve in some families; however, adaptation of the family can be negatively affected in some patients due to the absence of this type of support related to the uncertainty and fear (Dedeli et al., 2008; Kinsinger et al., 2011). Accordingly, the results of the present study are consistent with the findings reported in the literature and also suggest that family members have an active role in the fight against cancer.

Of the participants, $38.3 \%$ and $35.2 \%$ reported that they received support from doctors and nurses, respectively, whereas the score of social support from nurses was found to be low. In the study by Ozyurt (2007), social support to cancer patients from healthcare workers was low (29.3\% from doctors and $17.4 \%$ from nurses). According to Akdeniz (2012), because nurses are in a close relationship with the patients, it is very important in terms of adaptation to the cancer to determine the needs of the breast cancer patients and to give social support by nurses. With the main objective of "helping people", nurses should directly communicate with the patient and healthy individuals and also should help the patients develop their self-esteem and determine their future by ensuring participation of the individual, family, friends, social groups and population in all stages of healthcare (Birol, 2004).

The mean CPSSS score of the participants was 134.85 \pm 9.35 . The subscores RS and ES were higher than the IS subscore. This finding may be because most of the patients reported no social support from healthcare professionals. Shealby et al. (2008) studied women with breast cancer and reported high social support scores; they concluded that social support is an important source for women with breast cancer. Kroenke et al . (2006) followed 2835 women between 1992 and 2002 in terms of social support and reported that isolated women had 2-times higher mortality compared to the socially active women. The authors concluded that this factor is attributable to the lack of accessing care services, particularly from friends, relatives and children (Kroenke et al., 2006).

In the present study, social support was higher amongst women aged $<40$ years compared to other age groups. Ogce et al (2007) reported high level of social support in Turkey. According to the Turkish family structure report (2011), most Turkish families are nuclear (70\%), 96\% of the individuals marry only one time, and $58.5 \%$ of the married women and $65.9 \%$ of the married men define their spousal relationship as "very good". This difference may be because women aged $<40$ years usually live with their spouse and children and are more active in their social life and older women usually lose their spouse, spend more time at home and their social relationships deteriorate. Novotny et al. (2010) have found lower social support scores in female breast cancer patients aged younger than 50 years compared to those aged 65 years or over. The authors concluded that the lower social support found in younger patients was because they usually have smaller social support groups, do not have a spouse or partner and are more interested in their business career than family life (Novotny, 2010).The informational support subscore was significantly higher in participants younger than 40 years compared to those older than 60 years. This difference might exist because illiteracy is common, and educational levels are lower in women aged 65 years or over, suggesting that informational support could not be provided (Turkey Statistical Institute, 2013).

In the present study, social support increased with higher educational level. Although emotional support increased with higher educational level, reliance support was higher in primary school graduates compared to high school graduates. Cam et al. (2009) reported similar results, and the increased educational level is considered a positive factor that provided a wide social network and therefore broader social relationships. Moreover, in women with gynaecological cancers, social support has been reported to be adequate and to increase with higher educational level, financial status, employment status and knowledge of the diagnosis (Ayaz et al., 2008).

Social support was perceived as higher amongst participants with a better income level. Shelby et al. (2008), in contrast, found a negative association between the income level and psychosocial concerns in women with breast cancer. It is well known that financial power makes people feel safer and decreases anxiety (Shelby et al., 2008). Previous studies have also suggested that increased self-reported income level is associated with higher social support (Cam et al., 2009, Dedeli et al., Ayaz et al., 2008).

In terms of the CPSSS scores of the participants according to the disease stage, self-reported social support level was slightly higher in patients with stage 4 disease with no significant difference compared to other groups. This finding is because the need for care increases with advancing disease.

The social support level perceived by the patients who reported social support from the spouse, child(ren) and friends was high. Ayaz et al. (2008) reported higher social support in women who reported social support from family members than in those receiving support from friends (Ayaz et al., 2008).

The mean SIAS score was $34.30 \pm 9.35$ in the present study. Bakht and Najafi (2010) found poorer body image in women who underwent mastectomy compared to healthy women. Moreover, Fobair et al. (2006) reported that women usually have body image concerns and sexual problems during the first few months after the mastectomy and usually have more problems because of the changes related to the mastectomy, hair loss related to the chemotherapy, weight loss/gain and the thought of 
not being understood by the spouse.

Body image anxiety was higher in women aged 4050 years compared to the other age groups. Fobair et al. (2006) found that $50 \%$ of the female breast cancer patients aged 50 years or younger had concerns about their physical appearance. Most women experience menopause at approximately 40-50 years old and is usually associated with sexual role loss. In addition to menopause, breast cancer patients experience the problems associated with the breast - a sexuality symbol - and experience loss of physical, social and role functions (Michael et al., 2000; Okanl1, 2004). The additive effect of these two traumatic events might result in higher social appearance anxiety in women aged 40-50 years. Avis et al. (2006) reported that women diagnosed with breast cancer usually have more concerns about early menopause and pregnancy, and sexual function loss usually represents a greater problem than sexuality with a moderate concern about body image.

Social appearance anxiety was higher in primary school and high school graduates and the anxiety increased with higher income level (but the finding was not statistically significant). Moreover, social appearance anxiety was lower in women who were unaware compared to aware of the disease stage.

In the present study, social appearance was lower amongst women who received social support only from friends. Avc1 et al. (2009) studied women who underwent mastectomy and reported that $55.9 \%$ vs. $35.6 \%$ of the women report that their marriage was affected from the mastectomy in a negative vs. positive way. In our society, families avoid discussing the disease and its negative outcomes and avoid contact with the patient. Moreover, a diagnosis of cancer may have adverse effects on family members because of the concerns about genetic predisposition, role changes, and financial burden of the disease and because of being unfamiliar about helping the patient, resulting in inadequacy of the support given (Dedeli et al., 2008; Ozbas, 2005). In a previous study, the spouses of the women with cancer have been reported to be unready for regarding the physical and emotional status of the patient and to have difficulty in problem solving and coping with this situation (Babaoglu and $\mathrm{Oz}$, 2003). Therefore, having the opportunity to discuss the disease and its negative effects with friends may help the patients adapt to the disease and decrease the social appearance concerns.

In the present study, participants who received social support from health professionals had less social appearance anxiety and those who received social support from other healthcare workers or no support had more social appearance anxiety. The social support from healthcare professionals is known to increase knowledge levels and provide reliance to the patients, increasing their adaptation to the disease process (Usta, 2011). Therefore, social support from healthcare professional can decrease social appearance anxiety in female breast cancer patients.

Participants who reported a high level of social support had less social appearance anxiety. Social support increases self-esteem, decreases hopelessness and loneliness, and augments the sense of self (Landmark et al., 2002). In their study, Akdeniz (2012) reported a positive correlation between effective methods for coping with stress and the harmony between spouses, in which more effective coping methods are developed by increasing spouse harmony for married women with breast cancer. Cam et al. (2009) found that breast cancer patients living alone had higher scores on a psychosocial adaptation scale compared to those living in a nuclear or patriarchal family. It has also been reported that sense of self, social stress, social support, psychological support, sense of control, emotional problems, disease stage, surgical option, symptoms, physical ability, disease perception, coping methods and relationships and cooperation with healthcare professionals are all effective in helping patients adapt to the disease (Cam et al., 2009).

In conclusion, oncology nurses should regularly monitor social support and social appearance anxiety in female breast cancer patients and, if needed, should plan and meet the appropriate nursing implementations to help the patients maintain their physical and psychosocial health.

\section{References}

Abeloff MD, Wolf AC, Weber BL et al (2008). Cancer of the breast in: Abeloof's Clinical Oncology (Eds: Abeloff, M.D., Armitage, J.O., Niederhuber, J.E., Kastan, M.B., Mckenna, W.G.) Churchill Lingstone, fourth ed. Philadelphia, 95.

Abu-Helalah M, Al-Hanaqta M, Alshraideh H, Abdulbaqi N, Hijazeen J (2014). Quality of life and psychological wellbeing of breast cancer survivors in Jordan. Asian Pac J Cancer Prev, 15, 5927-36.

Akdeniz BE (2012). The analysis of the relationship between marital adjustment and coping strategies in married women with breast cancer. Journal of Psychiatric Nursing, 3, 53-60.

Alacacioglu A, Ulger E, Varol U, et al (2014). Depression, Anxiety and sexual satisfaction in breast cancer patients and their partners-Izmir Oncology Group Study. Asian Pac $J$ Cancer Prev, 15, 10631-636

American Cancer Society, 2014. Cancer facts and figures 2014. Atlanta, $\mathrm{p}: 3$.

Ardahan M (2006). Social support and nursing. J University School of Nursing, 9, 68-76.

Aslan O, Sekmen K, Komurcu S, Ozet A (2007). Hope in patients with cancer. Journal of Cumhuriyet University School of Nursing, 11, 18-25.

Avcı AI, Okanlı A, Karabulutlu E, Bilgili N (2009). Women's marital adjustment and hopelessness levels after mastectomy. European J Oncol Nurs, 13, 299-303.

Avis NE, Crawford S, Manuel J (2005). Quality of life among younger women with breast cancer. J Clin Oncol, 23, 3322-30.

Ayaz S, Efe YS, Korukoglu S (2008). Level of perceived social support of patients with gynaecological cancer and affecting factors. Turkiye Clinics J Med Sci, 28, 880-885.

Babaoglu E, OzF (2003). The relationship between psychological and social problems of the spouses who cared for the terminal cancer patients. J Research and Development in Nursing, 2, 24-34.

Bahar A (2006). Psychosocial approach to cancer patients. Journal of Ataturk University School of Nursing 10, 105-112.

Bakht S, Najafi S (2010). Body image and sexual dysfunctions: comparison between breast cancer patients and healthy women. Procedia Social and Behavioral Sciences, 5, 1493-7.

Bilge A, Cam O (2008). Investigation of women's styles of coping with stress in the prevention of cancer and their health 
beliefs. Anatolian JPsychiatry, 9, 16-21.

Birol L (2004). Nursing Process, Impact Printing Publishing Ltd. Sti., Izmir, p:24.

Cam O, Saka S, Gumuş A (2009). Investigation of factors affecting psychosocial adjustment of patients with breast cancer. J Breast Health, 5, 73-82.

Cavdar I (2006). Sexual problems of the patients who suffer from breast carcinoma. J Breast Health, 2, 64-66.

Dedeli O, Fadıloglu Ç, Uslu R (2008). A survey of functional living and social support in patients with cancer. J Medical Oncology, 28, 132-9.

Dincer U, Kaya E, Cakar E, Kıralp MZ, Dursun H (2007). Effectiveness of comprehensive rehabilitation and home exercise program for the treatment of medium and longterm disability depends on mastectomy. Turkish J Physical Medicine Rehabilitation, 53, 138-43.

Dogan T (2010). The Turkish adaptation of brief fear of negative evaluation scale: the validity and reliability study. J Hacettepe University Education Science, 39, 151-9.

Eylen B (2002). A study on the reliability and factor structure on the validity of the social support scale. J Uludag Univ Education Science, 15, 109-17.

Fobair P, Stewart SL, Chang S, et al (2006). Body image and sexual problems in young women with breast cancer. Psychooncology, 15, 579-94.

Kinsinger SW, Laurenceau JP, Carver CS, Antoni MH (2011). Perceived partner support and psychosexual adjustment to breast cancer. Psychology and Health, 26, 1571-88.

Kronke CH, Kubzansky LD, Schernhammer ES, et al (2006). Social Networks, Social support and survival after breast cancer diagnosis. J Clinical Oncology, 7, 1105-12.

Landmark TB, Strandmark M, Wahl A, 2002. Breast cancer and experiences of social support: a qualitative study of 10 women with newly diagnosed breast cancer. $J$ Advanced Nursing, 16, 216-223.

Manandhar S, Shrestha DS, Taechaboonsermsk P, Siri S, Suparp J (2014). Quality of life among breast cancer patients undergoing treatment in national cancer centers in Nepal. Asian Pac J Cancer Prev, 15, 9753-7.

Michael YL, Kawachi I, Berkman LF, et al (2000). The persistent impact of breast carcinoma on functional health status: Prospective evidence from the nurses' health study. Cancer, 89, 2176-86.

National Mastectomy and Breast Reconstruction Audit Fourth Annual Report (2011).ical effectiveness unit, royal college of surgeons of clin England. http://data.gov.uk/dataset

Novotny PJ, Smith DJ, Rummans TA, et al (2010). A pilot study assessing social support among cancer patients enrolled on clinical trials: A comparison of younger versus older adults. Cancer Manangement and Research, 2, 133-142.

Ogce F, Ozkan S, Baltalarli B (2007). Psychosocial stressors, social support and socio-demographic variables as determinants of quality of life of Turkish breast cancer patients. Asian Pac J Cancer Prev, 8, 77-82.

Okanl1 A (2004). Psychosocial effects of mastectomy in women. Intern J Human Sciences, 1-6.

Ozbas A (2005). Problems in families with breast cancer and solution. J Breast Health, 2, 115-117.

Ozyurt BE (2007). A descriptive study of the perceived level of social support for cancer patients. J Crisis, 15, 1-15.

Republic of Turkey Ministry of Health (2012). Statistics Yearbook, Synthesis Printing Publishing, Ankara, p: 23-33.

Rizalar S, Ozbas A, Akyolcu N, Gungor B (2014). Effect of perceived social support on psychosocial adjustment of Turkish patients with breast cancer. Asian Pac J Cancer Prev, 15, 3429-34.

Sahin ZA, Polat H, Erguney S (2009). Determination of burden care for caregivers of cancer patients receiving chemotherapy. J Ataturk University School of Nursing, 12, 1-9.

Shelby RA, Crespin TR, Gregorio SMW, et al (2008). Optimisim, social support, and adjustment in african american women with breast cancer. J Behaviour Medicine, 31, 433-44.

Tan M, Karabulutlu E (2005). Social support and hopelessness in turkish patients with cancer. Cancer Nursing, 28, 236-40.

Turkey Statistical Institute, Women in Statistics, 2013. Turkey family structure research, p:122, http://www.tuik.gov.tr/ PreHaberBultenleri.do?id=16056.

Ucar T, Uzun O (2008). Examination of effect on body image, self-esteem and marital adjustment of mastectomy in women with breast cancer. J Breast Health, 4, 162-168.

Usta YY (2012). Important of social support in cancer patients. Asian Pacific J Cancer Prev, 13, 3569-72.

Winters ZE, Balta V, Thomson HJ, et al (2011). Phase III development of the european organization for research and treatment of cancer quality of life questionnaire module for women undergoing breast reconstruction. Br J Surg, 101, 371-82.

World Health Organization (2004). Prevention of Mental Disorders, Effective Interventions and Policy Options. 